Article

\title{
mRNA Transcriptomic Profiling of Human Hepatocellular Carcinoma Cells HepG2 Treated with Catharanthus roseus- Silver Nanoparticles
}

\author{
Nur Asna Azhar ${ }^{1}$, Siti Aishah Abu Bakar,1,2, Marimuthu Citartan³, Nor Hazwani Ahmad ${ }^{{ }^{*}}$ \\ 1 Oncological and Radiological Sciences Cluster, Advanced Medical and Dental Institute, Universiti Sains \\ Malaysia, Bertam 13200 Kepala Batas, Penang, Malaysia; nurasnaazhar@gmail.com, aishah5abuba- \\ kar@gmail.com, norhazwani@usm.my \\ 2 Faculty of Bioresources and Food Industry, Universiti Sultan Zainal Abidin, Besut Campus, 22200 Besut, \\ Terengganu, Malaysia; aishah5abubakar@gmail.com \\ 3 Infectomics Cluster, Advanced Medical and Dental Institute, Universiti Sains Malaysia, Bertam 13200 \\ Kepala Batas, Penang, Malaysia; citartan@usm.my \\ * Correspondence: norhazwani@usm.my ; Tel.: +604-5622530
}

\begin{abstract}
Background: The demand in the development of cancer nanomedicine has increased due to various limitations in conventional cancer therapy. This study assessed the mRNA transcriptomic profiling of human HepG2 cells exposed to C. roseus-AgNPs. Methods: The proliferative activity of hepatocellular carcinoma (HepG2) and normal human liver (THLE3) cells treated with $C$. roseus-AgNPs were measured using MTT assay. The RNA samples were extracted and sequenced using BGIseq500 platform. This is followed by data filtering, mapping, gene expression analysis, DEG analysis, GO analysis, and pathway analysis. Results: The mean IC ${ }_{50}$ values of $C$. roseus-AgNPs on HepG2 was $4.38 \pm 1.59 \mu \mathrm{g} / \mathrm{mL}$ while on THLE3 cells was $800 \pm 1.55 \mu \mathrm{g} / \mathrm{mL}$. Transciptomic profiling revealed an alteration of 296 genes. C. roseus-AgNPs induced the expression of stress-associated genes such as MT, HSP and HMOX-1. Cellular signaling pathways were potentially activated through MAPK, TNF and TGF pathways that responsible for apoptosis and cell cycle arrest. The alteration of ARF6, EHD2, FGFR3, RhoA, EEA1, VPS28, VPS25, TSG101 indicated the uptake of $C$. roseus-AgNPs via both clathrin-dependent and clathrin-independent endocytosis. Conclusions: This study provides the new insights on gene expression study of biosynthesized AgNPs on cancer cells. The cytotoxicity effect is mediated by the aberrant gene alteration, and more interestingly the unique selective antiproliferative properties indicates the C. roseus-AgNPs as an ideal anticancer candidate.
\end{abstract}

Keywords: C. roseus; HepG2; silver nanoparticles; AgNPs; mRNA; transcriptomic; gene expression; oxidative stress; apoptosis; cell cycle.

\section{Introduction}

Nanoparticles are materials or discrete clusters of atoms having dimensions within 1-100 nm [1]. Having large surface area-to-volume ratio with unique biological properties, nanoparticles have gained immense usage in the early diagnosis and treatment of cancer, application of which is termed as nano oncology [2,3]. Nanoparticles can offer an alternative to the current conventional chemotherapeutic agents which although exhibit high efficacy in killing cancer cells, still suffer from significant drawbacks due to the poor specificity in causing severe damage to healthy cells [4]. Amongst various nanoparticles, silver nanoparticles (AgNPs) have been reported to demonstrate a significant biological 
effect, particularly in the healthcare industry [5, 6]. Concurrently, the market demand for eco-friendly, hazard-free, and cost-effective synthesis of silver nanoparticles was higher as many of the common nanoparticles production methods involved hazardous chemicals and high energy- consuming [7]. One of the most effective biogenic approach is to use plant extract that contains metabolites, which able to enhance the reduction silver ions. Plant extract-mediated silver nanoparticles synthesis is found to have a promising anticancer property. Plant extract-based synthesis is largely favoured due to the lower degree of adverse effect as well as low cost of synthesis that enables large scale production. Moreover, biological active ingredients or phytomolecules in the plant extract act as the reducing agents to promote the synthesis of AgNPs [8]. Previous study has corroborated the anticancer property of silver nanoparticles, for examples silver nanoparticles synthesized using Acalypha Indica, which exhibited anti-cancer activity against human breast cancer cell line (MDA-MB-231) [9]. In another study, silver nanoparticles synthesized using leaf extract of Tropaeolum majus L. also demonstrated anti-cancer properties on MCF7 cell line [10]. These findings cumulatively proved the anti-cancer property of the biogenic silver nanoparticles.

Previously, Catharanthus roseus (C. roseus) was demonstrated as a reducing agent to synthesize silver nanoparticles. $C$. roseus is commonly known as periwinkle which belongs to Apocynaceae testing [11]. This plant is very synonymous with its content, indolomonoterpenic alkaloids vincristine and vinblastine [12]. These compounds are commonly used in the treatment of several malignant conditions, such as Hodgkin's and non-Hodgkin's lymphomas, acute lymphoblastic leukaemia, neuroblastoma, breast carcinoma, among others [13]. These alkaloids may be responsible for the reduction of the silver ions to silver nanoparticles and at the same time exert its function by disrupting the mitotic spindle apparatus of microtubules through tubulin interaction, thus blocking mitosis process, and arresting the cancer cells during metaphase [14].

The anti-cancer property of silver nanoparticles is very well-acknowledged by now and the way forward is to understand its mechanism at the molecular level. This is achievable via transcriptome analysis, a holistic view of all the gene expression. An overview or snapshot of the gene expression landscape could reveal the intricate molecular network that underlies the myriad of biological processes in a cell. As compared to hybridizationbased RNA quantification methods such as microarray analysis, this sequencing-based transcriptome detection can perform well within a wide range of circumstances, where this method could quantify gene expression with low background, high accuracy, and high reproducibility levels with significant dynamic range transcriptome analysis is able to detect subtle changes in gene expression, mutations, splice variants and fusion genes that cannot be identified by microarrays [15].

Fuelled by the intriguing capacity of the transcriptome analysis, in this study, we endeavoured to carry out a mRNA transcriptome profiling of the human hepatocellular carcinoma cell (HepG2) treated with silver nanoparticles synthesized using an aqueous extract of $C$. roseus. The human hepatocellular carcinoma cell (HepG2) was used as a representative in vitro cancer cell line model, due to its known well-characterized property of the cell line and its wide usage in many toxicity studies for screening hepatotoxic compounds [16]. To the best of our knowledge, there was no study reported on the transcriptomic profiling of cancer cells treated with plant extract -mediated synthesized silver nanoparticle. As such, this study is the first study that focuses on the transcriptomic profiling of cancer cells treated with silver nanoparticles synthesized using plant extract. This study can be a significant step in identifying potential genes that are regulated by the treatment of C. roseus-AgNPs on HepG2 cells, which will lead to the establishment of the underlying molecular network of the mechanistic actions of the silver nanoparticles.

\section{Materials and Methods}




\subsection{Preparation of cell line}

The hepatocellular carcinoma cell line HepG2 used in this study was purchased from American Type Culture Collection ATCC $®$ HB-8065 ${ }^{\mathrm{TM}}$. Complete RPMI-1640 medium supplemented with $10 \%$ heat-inactivated fetal bovine serum, $1 \%$ penicillin-streptomycin $(\mathrm{v} / \mathrm{v})$ and $1 \%$ L-glutamine $(\mathrm{v} / \mathrm{v})$ was used to culture and maintain the cells. All the reagents were purchased from Nacalai Tesque, Japan. Meanwhile, normal liver cell line (THLE-3) (American type culture collection (ATCC), USA) was cultured in Bronchial Epithelial Cell Growth Basal Medium (BEGM) (Lonza, USA) supplemented with frozen additives without gentamycin/Amphotericin (GA) and Epinephrine, 5ng/mL EGF, 70ng/mL Phosphoethanolamine and $10 \%$ fetal bovine serum. The incubator used for the cell culture work was set at $37^{\circ} \mathrm{C}$ with $5 \%$ CO2 (Shellab, USA). Upon reaching $80 \%$ confluency, the cells were subcultured and transferred into new cell culture flasks. The cells were seeded at a concentration of $1 \times 10^{5}$ cells $/ \mathrm{mL}$.

\subsection{Preparation of C. roseus-AgNPs}

The C. roseus-AgNPs used in this study has been successfully synthesized, optimized, and characterized in our previous study [5]. The optimized C. roseus-AgNPs consist of $10 \%$ of $C$. roseus aqueous extract and $5 \mathrm{mM}$ of silver nitrate $\left(\mathrm{AgNO}_{3}\right)$ solution. The mixture was allowed to react in a dark environment at room temperature for 24 hours until the color changes from light yellowish to dark brownish. The mixture was then collected and centrifuged for 15 minutes at 10,000 rpm. The supernatant was discarded while the pellet was collected and freeze-dried.

\subsection{Cell Viability}

The proliferative activity of HepG2 and THLE-3 cells was assessed using Cell Titer 96® AQueous Non-Radioactive Cell Proliferation Assay Kit (Promega, USA) which consists of (3-(4,5-Dimethylthiazol-2-yl)-2,5-Diphenyltetrazolium Bromide) dye solution or also known as MTT and solubilisation solution. The method was performed as according to the manufacturer's protocol. HepG2 cells and THLE-3 cells were seeded in a 96-well plate (Eppendorf, Germany) at a concentration of $1 \times 105$ cells $/ \mathrm{mL}$. Cells were treated with C. roseus-AgNPs (Merck, USA) in serial dilution manner which were $1.96 \mu \mathrm{g} / \mathrm{mL}, 3.91$ $\mu \mathrm{g} / \mathrm{mL}, 7.82 \mu \mathrm{g} / \mathrm{mL}, 15.63 \mu \mathrm{g} / \mathrm{mL}, 31.25 \mu \mathrm{g} / \mathrm{mL}, 62.5 \mu \mathrm{g} / \mathrm{mL}, 125 \mu \mathrm{g} / \mathrm{mL}, 250 \mu \mathrm{g} / \mathrm{mL}, 500$ $\mu \mathrm{g} / \mathrm{mL}$, and $1000 \mu \mathrm{g} / \mathrm{mL}$. The cells were incubated for 24,48 , and 72 hours at $37^{\circ} \mathrm{C}, 5 \%$ incubator. Untreated cells were used as a control. Each of the sample sizes was done in triplicate. Following the indicated incubation time, each well was added with $20 \mu \mathrm{L}$ of MTT reagent and further incubated for 4 hours in a humidified 5\% CO2 incubator at 37 ${ }^{\circ} \mathrm{C}$. After 4 hours of incubation, $100 \mu \mathrm{L}$ of stop solution was added in each well and incubated for 1 hour to solubilize the formazan. The absorbance at $570 \mathrm{~nm}$ was recorded using a microplate reader (Bio Tek, USA). The half-maximal inhibitory concentration (IC50) values were calculated based on the following formula:

$$
\begin{aligned}
& \% \text { Cell Viability }=[\text { Mean OD sample }- \text { OD blank }] /[\text { Mean OD control }- \text { OD blank }] \times 100 \\
& \text { OD }=\text { Optical Density }
\end{aligned}
$$

\subsection{Treatment of HepG2 cells with C. roseus-AgNPs and total RNA extraction}

The HepG2 cells were seeded approximately at $1 \times 10^{5}$ cells $/ \mathrm{mL}$. The seeded cells were treated with C. roseus-AgNPs at a concentration of $4.95 \mu \mathrm{g} / \mathrm{mL}$, which is the IC50 value used in our previous study [5] and incubated for 72 hours at $37^{\circ} \mathrm{C}$ in a humidified atmosphere of 5\% CO2. Untreated HepG2 cells were used as a control. After 72 hours of exposure, the cells were washed with PBS and immediately lysed and homogenized in 
TRIzol $^{\mathrm{TM}}$ Reagent (Thermo Fisher, USA). Total RNA extraction was carried out using the manufacturers protocol. The resulting pellet was solubilized in RNAse-free water and was kept at $-80^{\circ} \mathrm{C}$ until further processing. The purity and concentration of RNA (260/280 ratio) were determined using Nanodrop 2000 spectrophotometer (NanoDrop Products, USA). The integrity of the total isolated RNA was assessed by Agilent 2100 Bioanalyzer (Agilent RNA 6000 Nano Kit).

\subsection{BGI sequencing}

All RNA samples were sent to BGI (BGI, Shenzen) for sequencing. The total RNA extracted was pre-processed for transcriptomic sequencing. The poly-A containing mRNA molecules were captured and purified using technique probe. The purified RNA molecules were reverse-transcribed into the first-strand cDNA, subsequently followed by the second-strand cDNA synthesis using Polymerase I and treatment with RNase H. The resulting product was purified and enriched with PCR amplification. The PCR amplicon was quantified by Invitrogen Qubit 2.0 Fluorometer (Thermofisher, USA). The amplicon libraries were pooled together to make a single-strand DNA circle (ssDNA circle). DNA nanoballs (DNBs) were generated from the ssDNA circle by rolling circle amplification and loaded into flow cell in which DNB binding sites are patterned nano-arrays. Sequencing was carried out using paired-end $100 \mathrm{bp}$ sequencing strategy on the BGIseq500 platform.

\subsection{Bioinformatics analysis}

High-quality genome sequencing data was developed by removing the adapter, poor quality and low complexity reads. The cleaned sequences were map onto the reference genome (hg19), subsequently followed by the identification of the novel genes, SNP (single nucleotide polymorphism), InDels (insertions and deletions) and the detection of gene splicing. Differential Gene Expressions (DGEs) were obtained by applying a paired, twotailed $t$-test to the calculated expression data of the treated and untreated samples. Gene Ontology (GO) analysis was used to analyse the enrichment of gene sets associated with biological processes, molecular functions, and cellular components. Kyoto Encyclopedia of Genes and Genomes (KEGG) analysis was carried out to permit the pathway annotation to the DEGs. $P$-value less than 0.1 is considered as statistically significant difference

\section{Results}

\subsection{Cytotoxicity of C. roseus-AgNPs on HepG2 Cells}

In this study, the cytotoxic effects of C. roseus-AgNPs were shown on HepG2 cells and normal liver epithelial cells, THLE-3 cells. Figure 1(a) shows the cytotoxicity effects of HepG2 cells after treatment with $C$. roseus-AgNPs. In comparison to the untreated cells, C. roseus-AgNPs significantly $(p<0.001)$ inhibited the proliferation of HepG2 cells at all concentrations and incubation periods in time- and dose-dependent manner, indicating the cytotoxic effect of C. roseus-AgNPs towards HepG2, with 7.79 \%, 21.59\%, and 30.15\% of cells were inhibited at the lowest concentration of C. roseus-AgNPs at 24, 48 and 72 hours, respectively. HepG2 cells showed a consistent percentage decrement of cell viability upon the treatment, and only $1.78 \%$ average of the cells survived between 24 to 72 hours of incubation at highest concentration of C. roseus-AgNPs. The percentage of C. roseus-AgNPs cytotoxicity compared to the untreated cells was used to determine the $\mathrm{IC}_{50}$ values as illustrated in Figure 1(b) where the IC 50 were $6.73 \pm 2.32 \mu \mathrm{g} / \mathrm{mL}, 3.67 \pm 0.32 \mu \mathrm{g} / \mathrm{mL}$, and $2.75 \pm 0.54 \mu \mathrm{g} / \mathrm{mL}$ at 24,48 , and 72 hours of incubation, respectively. Figure 1 (c) shows the effect of THLE-3 treated with $C$. roseus-AgNPs. The results demonstrate an intriguing finding, where the $C$. roseus-AgNPs demonstrated a substantial $(p<0.001)$ increment in THLE3 proliferation at concentrations of $1.96 \mu \mathrm{g} / \mathrm{mL}$ and $7.81 \mu \mathrm{g} / \mathrm{mL}$ for all incubation 
time. On the contrary, during all incubation times there was no significant difference at concentrations of $15.63 \mu \mathrm{g} / \mathrm{mL}$. However, at concentration $31.25 \mu \mathrm{g} / \mathrm{mL}$ to $1000 \mu \mathrm{g} / \mathrm{mL}, \mathrm{C}$. roseus-AgNPs significantly $(p<0.001)$ inhibited the proliferation of THLE3 cells as compared to untreated THLE3 cells. After 72 hours, approximately $55.78 \%$ of cells survived at the highest concentration of C. roseus-AgNPs. There was no IC 50 values at concentrations for 24 and 48 hours, but at 72 hours, the $\mathrm{IC}_{50}$ was recorded at $800 \pm 1.55 \mu \mathrm{g} / \mathrm{mL}$, as depicted in Figure 1(d). Based on the results, we observed that C. roseus-AgNPs was found to inhibit the growth of HepG2 cell line (mean $\mathrm{IC}_{50}=4.38 \pm 1.59 \mu \mathrm{g} / \mathrm{mL}$ ), Contrarily, C. roseus-AgNPs showed very weak inhibition activity toward THLE3 cells $\left(\mathrm{IC}_{50}=800 \pm 1.55 \mu \mathrm{g} / \mathrm{mL}\right)$.

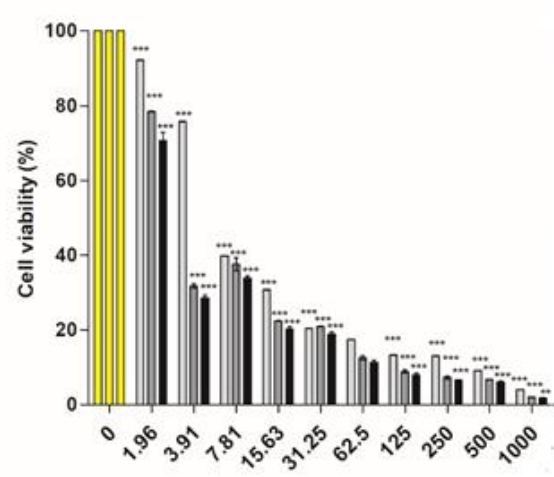

Concentration $(\mu \mathrm{g} / \mathrm{mL})$

(a)

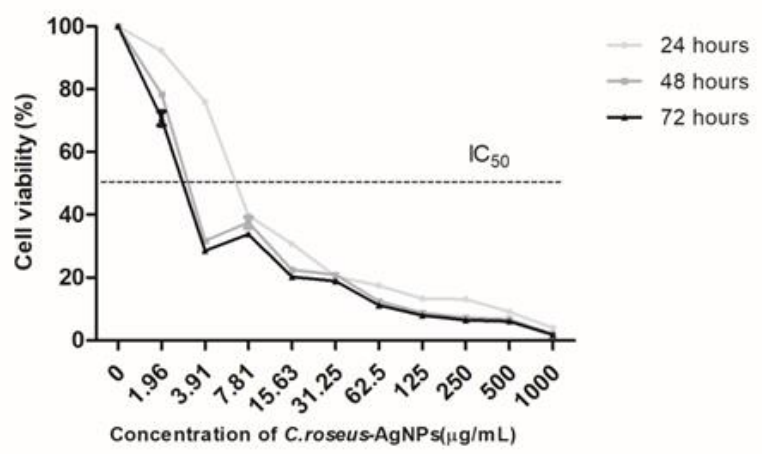

(b)

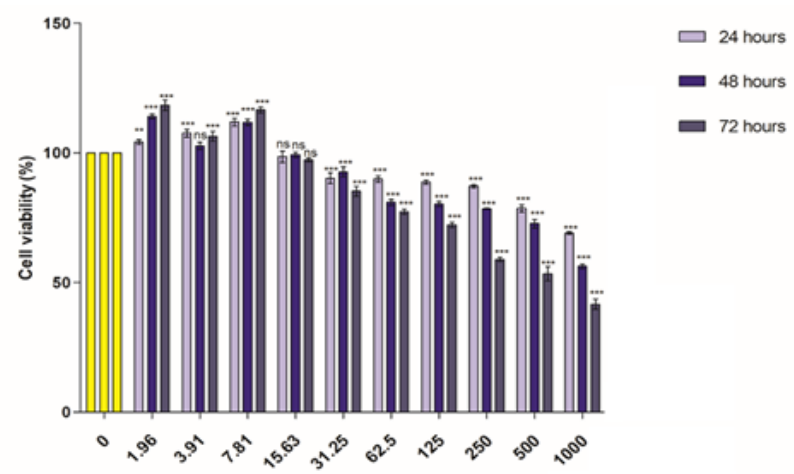

Concentration $(\mu \mathrm{g} / \mathrm{mL})$

(c)

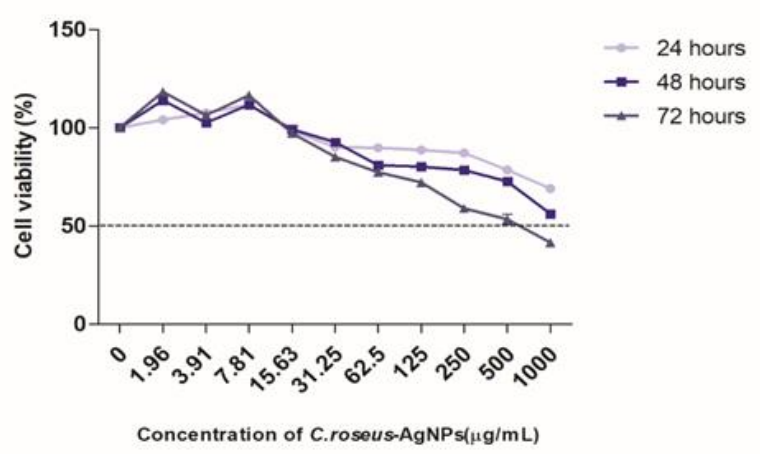

(d)

Figure 1. Figure 1(a) The cytotoxicity of HepG2 cell lines treated with different concentrations of C. roseus-AgNPs. (b) The IC50 of $C$. roseus-AgNPs on HepG2 cells. (c) The cytotoxicity of THLE3 cell lines treated with different concentrations of $C$. roseus-AgNPs. (d) The IC50 of C. roseus-AgNPs on THLE-3 cells. All experiments were done in triplicate, and the data represent means \pm standard deviations. The comparison between each concentration with untreated cells was done using two-way ANOVA with Dunnet post-test to detect any significant differences $\left({ }^{*} p<0.05 ;{ }^{* *} p<0.01 ;{ }^{* *} p<0.001\right.$; ns not significant)

\subsection{Quantitative and Qualitative Measurement of Total RNA}

Total isolated RNA was quantified using Bioanalyzer. As depicted in Figure 2 (a) and (b), representative electropherogram indicated two intact bands that are visible in each sample. These two bands represent $28 \mathrm{~s}$ and $18 \mathrm{~s}$ ribosomal RNA, respectively. RNA 
integrity number (RIN) was then determined, which is the value of the RNA integrity. The value that falls within a range between 8 to 10 showed an acceptable value of RIN (17). The RIN and ribosomal ratio values acquired for both untreated and C. roseus-AgNPs treated HepG2 cells were 9.6 and 9.4, respectively. Both RIN values were within the acceptable range.

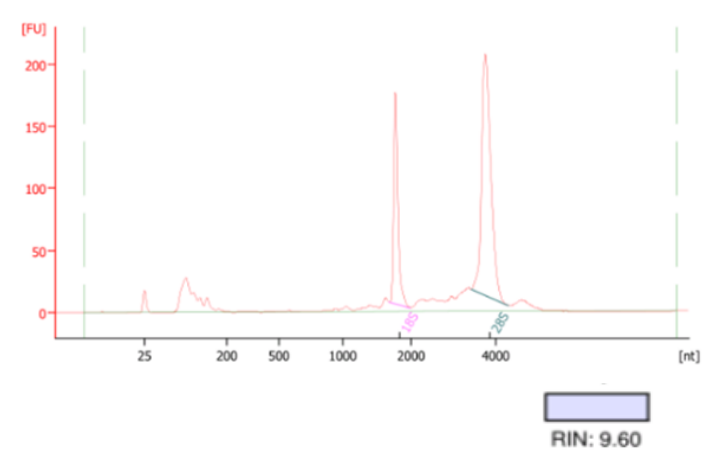

(a)
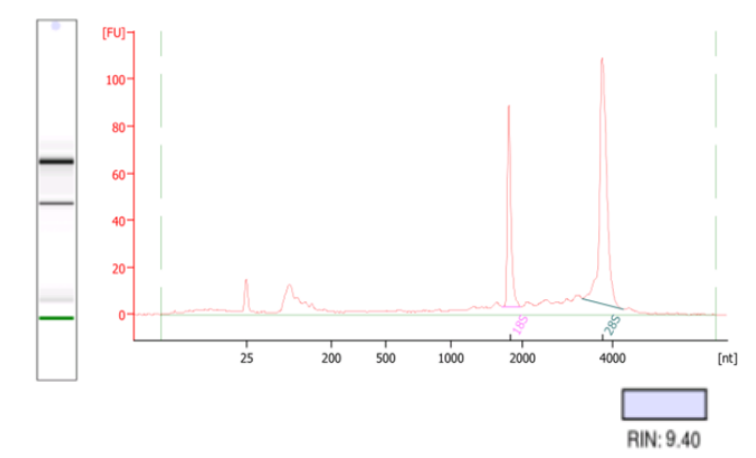

(b)

Figure 2. Representative electropherograms by bioanalyzer (a) The RNA samples for untreated HepG2 cells (b) the RNA samples for C. roseus-AgNPs treated HepG2 cells.

\section{3 mRNA Transcriptome sequencing}

\subsubsection{Sequencing data filtering}

In this project, two samples were sequenced using the DNBseq platform and about the resulting data were about $6.98 \mathrm{~Gb}$ bases per sample. The distribution of the base quality was shown in Figure 3. As can be observe from both Figure 3 (a) and Figure 3(b), the percentage of clean reads were $93.69 \%$ and $94.03 \%$ respectively.

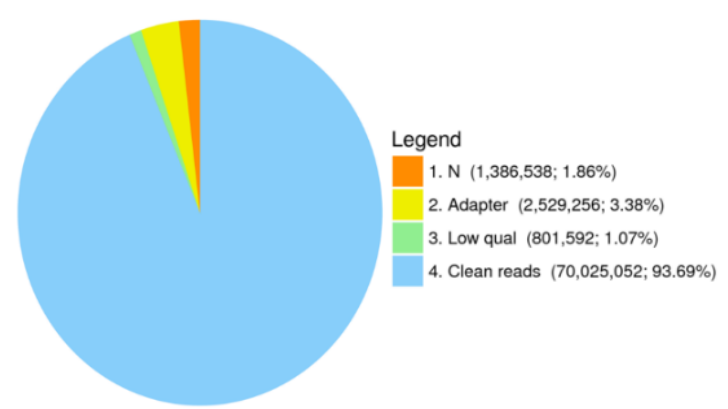

(a)

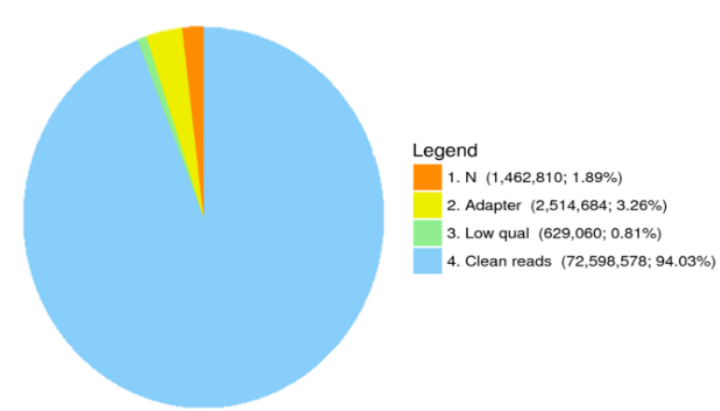

(b)

Figure 3. Filter composition of raw data. a) RNA samples for untreated HepG2 cells (b) RNA samples for C. roseusAgNPs treated HepG2 cells.

\subsubsection{Genome mapping}

After reads filtering, the clean reads were mapped to the reference genome using HISAT2 [18]. On average, $95.88 \%$ reads were found to be mapped to the population of human 
genomes and the consistency of the mapping result for each sample suggests that the samples were comparable. The mapping details are shown in Table 1.

Table 1: Summary of genome mapping.

\begin{tabular}{lccc}
\hline Sample & Total Clean Reads & Total Mapping Ratio & $\begin{array}{c}\text { Uniquely Mapping } \\
\text { Ratio }\end{array}$ \\
\hline Untreated HepG2 & $70,025,052$ & $95.94 \%$ & $76.60 \%$ \\
\hline $\begin{array}{l}\text { C. roseus-AgNPs } \\
\text { treated HepG2 }\end{array}$ & $72,598,578$ & $95.82 \%$ & $75.94 \%$ \\
\hline
\end{tabular}

\section{Gene Expression Analysis}

To get a complete reference for the gene mapping and expression, novel coding transcripts were merged with the reference transcripts, and clean reads were mapped to it using Bowtie2 [19]. The gene expression level for each sample was calculated with RSEM [20]. The result of this analysis is summarized in Table 2.

Table 2: Summary of gene mapping ratio.

\begin{tabular}{lccc}
\hline Sample & Total Clean Reads & Total Mapping Ratio & $\begin{array}{c}\text { Uniquely Mapping } \\
\text { Ratio }\end{array}$ \\
\hline Untreated HepG2 & $70,025,052$ & $66.79 \%$ & $63.92 \%$ \\
\hline $\begin{array}{l}\text { C. roseus-AgNPs } \\
\text { treated HepG2 }\end{array}$ & $72,598,578$ & $62.94 \%$ & $60.15 \%$ \\
\hline
\end{tabular}

The sufficiency of sequencing data for bioinformatics analysis was approached using sequencing data saturation analysis. As the number of sequenced reads increased, the number of identified genes also increased. On the other hand, when the number of sequenced reads reached a certain amount, the determining gene growth curve flattens, indicating the identified gene reached saturation. Figure 4 displays the saturation analysis for each sample.

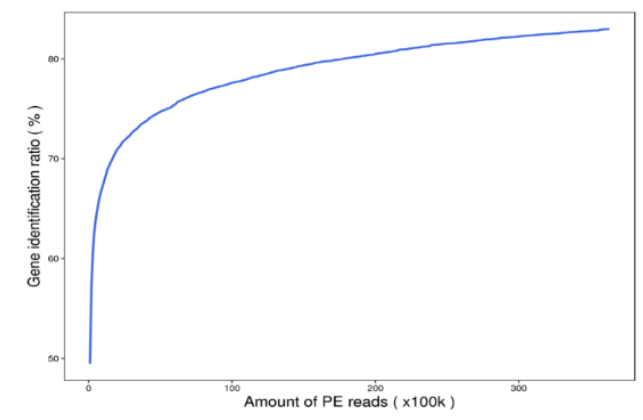

(a)

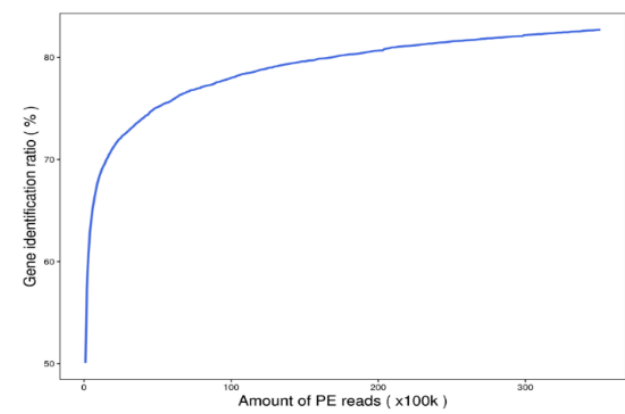

(b)

Figure 4. Saturation analysis (a) Untreated HepG2 cells (b) C. roseus-AgNPs treated HepG2 cells. 
Reads coverage and distribution of each detected transcript are shown in Figure 5 and Figure 6, respectively. This approach allows access to the excellent quality of the samples and sequencing data sufficiency by showing the completely covered transcripts and evenly distributed reads throughout the transcript. These results suggest that both untreated and treated HepG2 had an excellent sample quality and sufficient dasequencing. Correlation between samples was assessed by Pearson correlation coefficients calculations for all gene expression between the samples, as shown in Figure 7.

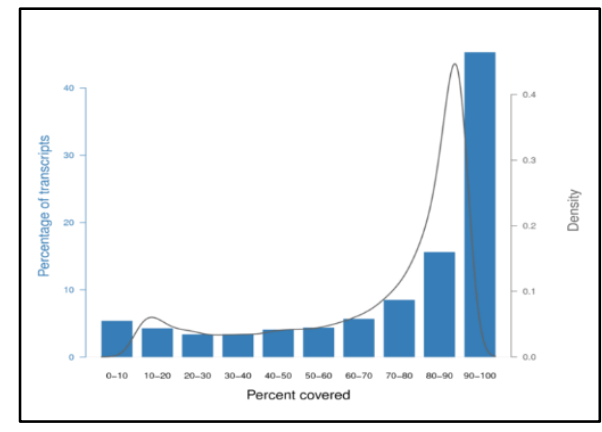

(a)

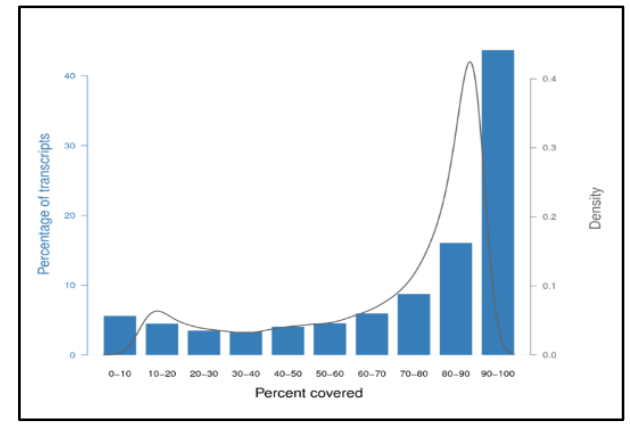

(b)

Figure 5. Read coverage on transcripts. The $X$-axis represents the read coverage. Left $Y$-axis represents the percentage of transcripts. The right Y-axis represents the density of transcripts. (a) Untreated HepG2 cells (b) C. roseus-AgNPs treated HepG2 cells.

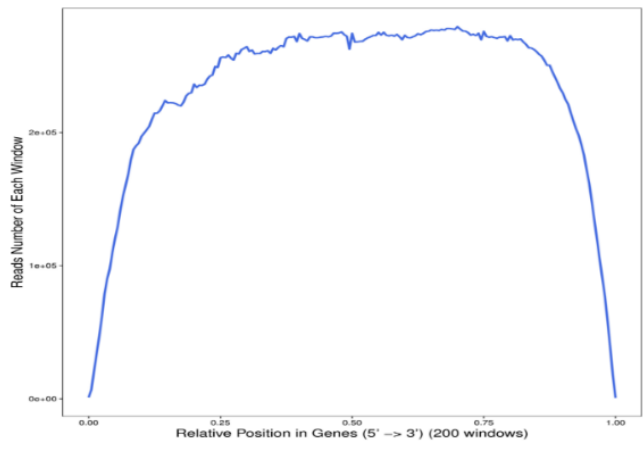

(a)

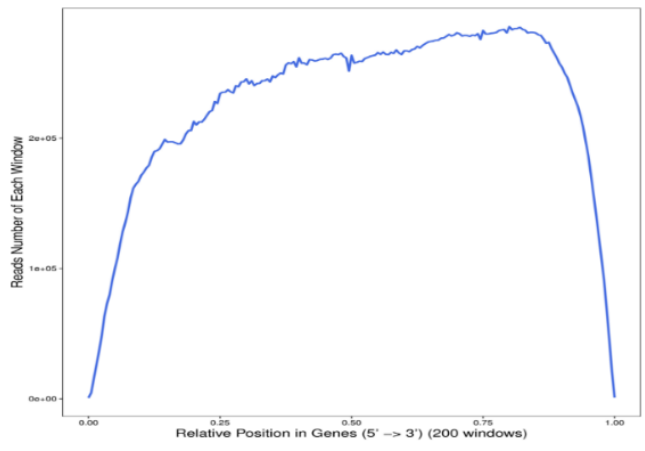

(b)

Figure 6. Read coverage on transcripts. The X-axis represents the position along with transcripts. Left $\mathrm{Y}$-axis represents the number of reads (a) Untreated HepG2 cells (b) C. roseus-AgNPs treated HepG2 cells.

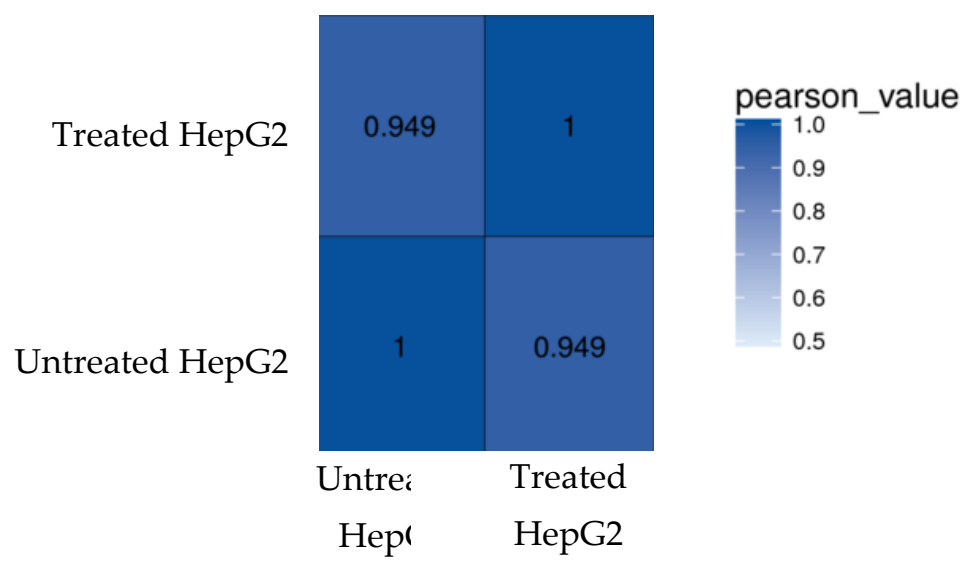

Figure 7. The correlation analysis between samples. The color represents the correlation coefficient.

\subsection{The identification of Differentially Expressed Genes}


Differentially expression genes (DEG) were determined by using DEseq2 and passion Dis algorithms. The distribution of DEG is summarized using the volcano plot as shown in Figure 8. The treatment of HepG2 cells with C. roseus-AgNPs revealed 296 DEGs, with 182 genes were upregulated while 114 genes were downregulated (Appendix A).

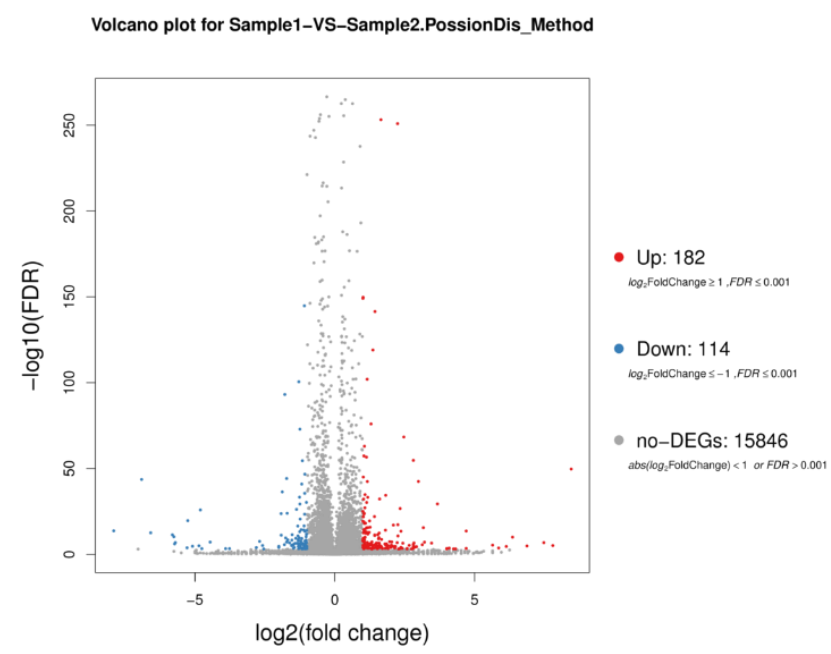

Figure 8. Volcano plot of DEGs. Red points represent upregulated DEGs. Blue points represent down-regulated DEGs. Grey points represent non-DEGs.

\subsection{Gene ontology analysis of DEG}

The identified DEGs were subjected to Gene ontology analysis. GO unveiled three ontologies which are related to molecular biological function, cellular component, and biological process. The classification result is depicted in Figure 9.

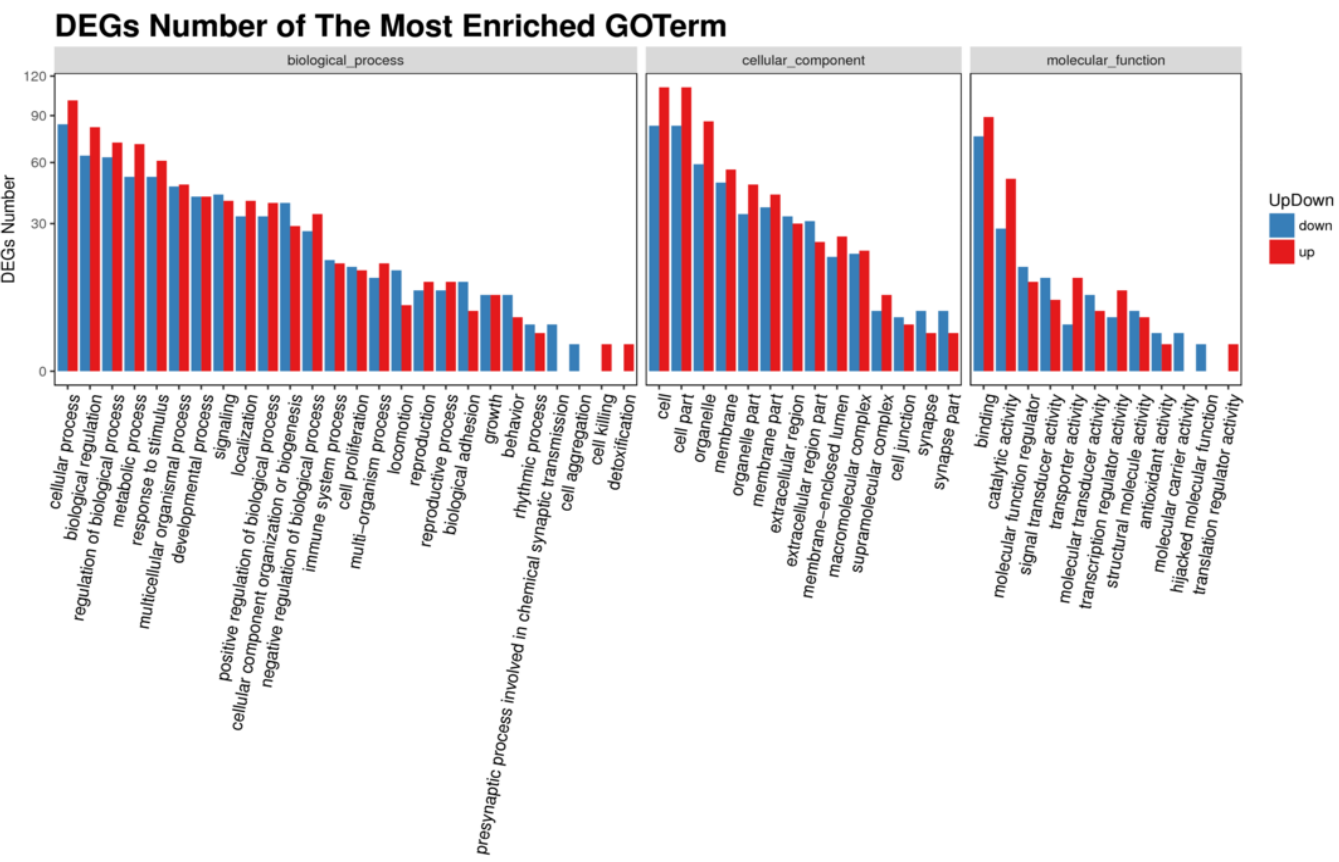

Figure 9. GO classification of upregulated and downregulated DEG. 
KEGG pathway classification and functional enrichment were generated based on DEGs. Pathway enrichment result is shown in Table 3 and the network enrichment is depicted in Figure 10.

Table 3: Pathway functional enrichment results.

\begin{tabular}{|c|c|c|c|c|}
\hline $\begin{array}{l}\text { Pathway } \\
\text { ID }\end{array}$ & Pathway & Genes & Hits & $\begin{array}{l}\text { Adj } P \\
\text { value }\end{array}$ \\
\hline K05200 & Pathway in cancer & $\begin{array}{l}\text { FAS, GADD45A, BAX, PMAIP, BID, JUN, } \\
\text { CXCL8, HMOX1, STAT1, FOS, CEBPA, } \\
\text { VEGFA, FGF5, EGF, RHOA, FADD, FH, } \\
\text { SMAD, MTOR, NFkBIA, CDKN1A, WNT4*, } \\
\text { WNT7A* FGFR3* BMP4 }^{*}, \text { CDK4* CDK2*, } \\
\text { MDM* }\end{array}$ & $29 / 530$ & $3.28 \mathrm{E}-12$ \\
\hline K04115 & $\begin{array}{l}\text { p53 signalling path- } \\
\text { way }\end{array}$ & $\begin{array}{l}\text { FAS, GADD45A, SERPINE, THBS1, CDK4, } \\
\text { BAX, CDK2, PERP, SESN1, SESN2, PMAIP1, } \\
\text { BID, IGFBP3*, MDM2* }\end{array}$ & $14 / 72$ & $1.28 \mathrm{E}-13$ \\
\hline K04210 & Apoptosis & $\begin{array}{l}\text { FAS, GADD45A, BAX, PMAIP1, BID, JUN, } \\
\text { FOS, FADD, NFKBIA, BCL2A1, ATF4, MCL1, } \\
\text { TNFSF10* RIPK1* }\end{array}$ & $14 / 136$ & 9.61E-10 \\
\hline K04144 & Endocytosis & $\begin{array}{l}\text { ARF6, RHOA, EHD2, FGFR3, HSPA6, } \\
\text { HSPA1L, VPS28, EEA1, VPS25, TSG101, } \\
\text { STAM, SMAD, EHD4, LDLR, TFRC* MDM2* }\end{array}$ & $16 / 244$ & 4.08E-08 \\
\hline K04010 & $\begin{array}{l}\text { MAPK signalling } \\
\text { pathway }\end{array}$ & $\begin{array}{l}\text { FAS, GADD45A, JUN, FOS, VEGFA, FGF5, } \\
\text { CDKN1A, EGF, ATF4, HSPA6, HSPA1L, } \\
\text { CDKN1A, HSPB1, DUSP1, NR4A1, EFNA4* } \\
\text { FGFR3*,ERBB3*, SKP2* }\end{array}$ & $16 / 295$ & 5.58E-07 \\
\hline K04668 & $\begin{array}{l}\text { TNF signalling path- } \\
\text { way }\end{array}$ & $\begin{array}{l}\text { FAS, JUN, FOS, FADD, NFKBIA, ATF4, } \\
\text { RIPK1* CCL2, NOD2, CCL20* }\end{array}$ & $10 / 110$ & 9.07E-07 \\
\hline K04350 & $\begin{array}{l}\text { TGF beta signalling } \\
\text { pathway }\end{array}$ & $\begin{array}{l}\text { THBS1, RHOA, SMAD2, SMAD4, BMP4, } \\
\text { SMAD7, BAMBI, BMP6 }\end{array}$ & $8 / 90$ & $1.66 \mathrm{E}-05$ \\
\hline K02010 & Cell cycle & $\begin{array}{l}\text { GADD } 45 A, S O X 15, C D K 4^{*}, C D K 2^{*}, M D M 2, S M \\
A D 2, S M A D 4, C D K N 1 A, P C N A^{*}, M C M 3^{*}, \\
S K P 2 *\end{array}$ & $9 / 124$ & 2.09E-05 \\
\hline K04978 & Mineral absorption & HMOX1, MT1F, MT1X, MT1H, MT1B, FTH1 & $6 / 51$ & 3.58E-05 \\
\hline
\end{tabular}


Figure 10. Network enrichment result. The darker the color indicates the highest enrichment pathways. The larger the area, the higher the degree of enrichment.

\section{Discussion}

\subsection{C. roseus-AgNPs exhibited anti-cancer properties with negligible effect on normal cells}

Our group has previously demonstrated the anti-cancer properties of C. roseus-AgNPs on cancer cells [21]. The anti-cancer properties of the C. roseus-AgNPs was estimated by IC 50 , which represents the concentration of C. roseus-AgNPs required to inhibit $50 \%$ of the total cells [22]. According to the IC $50(800 \pm 1.55 \mu \mathrm{g} / \mathrm{mL})$ observed at 72 hours, the THLE3 cells substantially $(P<0.001)$ inhibited only at very high concentrations of $C$. roseus-AgNPs. On the other hand, the IC ${ }_{50}$ of the C. roseus-AgNPs on the HepG2 cells was $4.38 \pm 1.59 \mu \mathrm{g} / \mathrm{mL}$. This study revealed that $C$. roseus-AgNPs showed a significant $(P<0.001)$ cytotoxicity towards HepG2 cells as compared to THLE3 cells. C. roseus-AgNPs can inhibit the progressive development of HepG2, while causing very insignificant toxicity to normal cells at low concentrations. Several studies have also shown that biosynthesized AgNPs show no toxicity against normal cells, while demonstrating cytotoxic effects against cancer cells. For example, a study by Halkai et al. (2019) showed that fungal derived AgNPs exerted against the human gingival fibroblast (HGF) cell line, while Sriram et al. (2010) also reported similar observations in their experiments, where AgNPs act as an anti-proliferative agent by effectively inhibiting the development of Dalton's lymphoma ascites (DLA) cell lines without causing toxicity on normal cell lines [23-28]. The findings from out study agreed with the previous reports, corroborating the potentiality of C. roseus-AgNPs as anti-cancer agent.

\section{2 mRNA transcriptome analysis identified 296 protein-coding genes}

An in-depth understanding of the anti-cancer properties of the C. roseus-AgNPs entails the identification of the genes that act in concert in orchestrating the effect. As transcriptome analysis can provide an overarching view of the gene expression profile under a certain condition or state, it was adopted in our effort to comprehend the underlying mechanisms of the anti-cancer activity of $C$. roseus-AgNPs against HepG2 cells. In the present study, the untreated HepG2 cells and C. roseus-AgNPs treated HepG2 cells were subjected to mRNA transcriptome analysis using BGI DNBseq Platform. As revealed by the mRNA transcriptome analysis, it was found out that the treatment of HepG2 cells with $C$. roseus-AgNPs has resulted in the regulation of 296 protein-coding genes, of which 182 genes were upregulated while 114 genes were downregulated, as shown in Figure8. 
GO analysis exhibited that the highest fraction of the regulated genes was involved in cellular and signaling response' followed by 'biological regulation', 'regulation of biological process', 'metabolic process' and 'response to stimulus' (Figure 9). The underlying pathways regulated by the genes are p53 signaling pathway, pathway in cancer, apoptosis pathway, endocytic pathway, MAPK signaling pathway, TNF signaling pathway, TGF signaling pathway, cell cycle pathway and mineral absorption pathway.

\subsection{C. roseus-AgNPs induced the expression of stress-associated genes such as MT, HSP and HMOX-1}

C. roseus-AgNPs treatment of the HepG2 cells was found to upregulate several members of the gene isoforms that encode metallothionein, such as MT1F, MT1X, MT1H, MT1B. Metallothioneins (MTs) are intracellular proteins that contain approximately $30 \%$ thiolcontaining cysteine residues, which can bind several cytotoxic agents, including platinum compounds, alkylating agents, and metal ions such as zinc and copper [29]. MTs also regulate various patho-physiological processes such as apoptosis, angiogenesis and could also act as radical scavengers by protecting the cells from free radicals [30]. As such, an increased level of MT is an indicator that the cells were undergoing 'stress' and the cells are striving to mitigate the cytotoxic effect of the anticancer drug, in this case C. roseusAgNPs [31]. This finding is also in agreement with the findings by Woo et al. (2006), who reported that Javanese medaka, a type of seawater organisms showed MT upregulation upon exposure to AgNPs [32]. On the other hand, heat-shock genes such as HSPA1L, HSPB1, and HSPA6 were also found to be upregulated in HepG2 cells exposed to C. roseusAgNPs. HSPs are upregulated by stress signals such as high temperature, decreased availability of oxygen, infectious agents, and inflammatory mediators. [33]. The increased expression level of HSPs is needed to counteract the stress, which is induced by C. roseusAgNPs in this study. Furthermore, the up-regulation of oxidative stress-related genes heme oxygenase-1 (HMOX-1) was also documented in our experiment. HMOX-1 is a ROS sensor that has antioxidant and anti-inflammatory properties [34]. During stress condition, HMOX-1 catalyze the degradation of the Heme group into biliverdin, carbon monoxide, and iron [35]. Similar increased expression of HMOX-1 was also observed by Gurunathan et al., (2018) in mouse embryonic fibroblast cells upon treatment with AgNPs [36]. Collectively, the upregulation of stress-response genes such as MTs, HSPs, and $H M O X-1$ in this study indicates that $C$. roseus-AgNPs exposure invokes the cell's defensive response in negating effects of cellular stresses caused by C. roseus-AgNPs. The increased expression of stress-response genes indirectly reflects on the cytotoxic effect of C. roseusAgNPs. In fact, we have also observed significant production of NO and ROS in our previous study upon treatment of HepG2 cells with by C. roseus-AgNPs [37]. These findings are substantial and in agreement with the previous findings, whereby upregulation of MTs, HSPs, and HMOX-1 were observed in cells exposed to AgNPs [38-40].

\subsection{C. roseus-AgNPs increased expression of tumor suppressor genes and apoptotic genes}

The most intriguing finding in our study is that C. roseus-AgNps treatment on HepG2 cells induces the expression of growth arrest and DNA damage inducible alpha (GADD45A) gene, which is a type of tumor suppressor gene that regulates processes such as DNA repair, cell cycle control, senescence, and genotoxic stress [41]. The expression of GADD45A gene in cell cycle inhibition is also regulated by $p 53$. p53 protein is involved in maintaining the genetic integrity and regulating the cellular response towards genotoxic stress by inducing cell cycle arrest or apoptosis to prevent tumorigenesis [42]. p53 is negatively regulated by murine double minute 2 (MDM2). Interestingly, our experimental findings demonstrated that MDM2 was downregulated in C. roseus-AgNPs treated HepG2 cells, suggesting that its inhibitory effect against p53 was ameliorated, causing the upregulation of $p 53$ gene. As such, the expression of $p 53$ gene elevates, causing the suppression of the proliferation of cancer cells. Sahua et al. (2015) reported similar 
observations in their study where under normal conditions, p53 was constitutively expressed, but is inactivated by its negative regulator, MDM2. However, during cellular stresses, MDM2 was downregulated which in turn caused the upregulation of p53 gene [43]. The upregulation of the $p 53$ gene is indicative of the anticancer effect of C. roseusAgNPs in amplifying the tumor suppressor activity of the cancer cells. Besides the upregulation of the tumor-suppressor genes, apoptotic-related genes Bcl-2-associated X (BAX) and Fas Cell Surface Death Receptor (FAS) were also found to be upregulated, suggesting the anticancer efficacy of the C. roseus-AgNPs in promoting apoptosis in cancer cells.

\subsection{C. roseus-AgNPs activated signal transduction pathway such as mitogen-activated protein kinase (MAPK) signaling pathway}

The MAPK pathway is a series of protein kinase cascade essential in regulating numerous physiological functions including inflammation, cell stress response, cell differentiation, cell division, cell proliferation, metabolism, motility, and apoptosis [44]. Treatment with C. roseus-AgNPs activated MAPK signaling pathway in HepG2 cells. In this study, several genes that are involved in MAPK pathways were found to be regulated such as FAS, GADD45A, P53, Transcription factor AP-1 (JUN), Proto-oncogene c-Fos (FOS). As indicated previously, GADD45A, a tumor suppressor gene which could also be involved in the MAPK signaling pathway was found to be upregulated upon treatment of the HepG2 cells with C. roseus-AgNPs. Increased expression of GADD45A conduces to baicalein-induced apoptosis and activation of MAPK signaling pathway [45]. In this study, activation of MAPK signaling pathway also upregulates p53 gene as mentioned previously, as MAP kinase phosphorylates and activates p53 protein in response to stressful stimuli induced by C. roseus-AgNPs [46]. Taken together, activation of MAPK pathway prepares the cell for counteracting actions such as inflammation, cell stress response, apoptosis upon treatment with $C$. roseus-AgNPs, which indirectly implies the anticancer properties harbored by these nanoparticles.

\subsection{C. roseus-AgNPs activated TNF signaling pathway}

TNF alpha is a pro-inflammatory cytokine that acts by binding to TNF receptor-1 (TNFR1) and TNF receptor-2 (TNF-R2) receptors, resulting in the recruitment of signal transducers that activate the effector, leading to the activation of caspases and two transcription factors, Nuclear factor- $k B(\mathrm{NF}-\mathrm{kB})$, as well as mitogen activated protein(MAP) kinases such as extracellular-signal-regulated kinase (ERK), p38, and c-Jun N-terminal Kinase (JNK), which will induce apoptosis and necrosis [47]. In this study, the treatment of $C$. roseus-AgNPs causing the upregulation of several genes that related to TNF signaling pathway such as Fas-Associated protein with Death Domain (FADD), NFKB Inhibitor Alpha (NF- Kbia), Activating Transcription Factor 4 (ATF4), Chemokine Ligand 2 (CCL2), Nucleotide Binding Oligomerization Domain Containing 2 (NOD2). FADD protein interacts directly with Tumor necrosis factor receptor type 1-associated death domain (TRADD), which are signal transducers that activate NF-kB and trigger apoptosis [48]. The overexpression of the FADD genes in our study suggests that treatment with C. roseusAgNPs eventually promotes apoptosis. Similar overexpression was also reported in the previous study, whereby AgNPs treated MDA-MB-436 cells showed increased in level of $F A D D$ gene [49]. In this study, the upregulation of ATF4 was also found. The overexpression of ATF4 was reported by Yorihiro Iwasaki et al. (2014), which happens in response to metabolic stresses caused by SFAs and ER stressors [50]. Receptor-interacting protein kinase 1 (RIPK1) gene is involved in the system that controls cell survival, signaling node in cell death and inflammation and cytokine production. The downregulation of RIPK1 gene in this study upon treatment with C. roseus-AgNPs can induce apoptosis via the cleavage activity of the caspase 3 associated pathway [51]. X. Qiu et al. (2019) reported similar observations in their experiments [52]. Chemokine Ligand 2 (CCL20) is known to enhance cancer cell progression [53]. The downregulation of CCL20 gene in this study 
suggests that $C$. roseus-AgNPs able to induce inflammation through TNF-related apoptosis-inducing ligand (TRAIL) as reported by previous study [54].

\subsection{C. roseus-AgNPs elicited the activation of TGF- $\beta$ signaling pathway}

The transforming growth factor $\beta$ (TGF)- $\beta$ signaling pathway plays a crucial role in controlling various fundamental aspects of cellular activities such as cellular growth, development, differentiation, and apoptosis [55]. As a secreted polypeptide, TGF- $\beta$ functions via receptor serine/threonine kinases and intracellular SMAD effectors [56]. TGF- $\beta$ acts as tumor suppressor at the early stage of cancer while it also acts as a pro-metastatic factor in the later stages of cancer [57]. Exposure of HepG2 cells to C. roseus-AgNPs activates TGF- $\beta$ signaling pathway. The effect of $C$. roseus-AgNPs is analogous to a previous study, whereby ellagic acid was found to exert anti-proliferation effects by activating TGF$\beta /$ Smad3 signaling pathway [58]. Transcriptome analysis also showed that isoforms of SMAD, which are part of TGF- $\beta$ pathway were also upregulated. Moreover, Bone morphogenetic proteins (BMPs) such $B M P 4$ and $B A M P 6$, which are extracellular signaling molecules that belong to TGF- $\beta$ pathway, were also upregulated. The tumor suppressor effect mediated by TGF- $\beta$ pathway was imparted upon treatment with $C$. roseus-AgNPs, which corroborates its anticancer property.

\subsection{The uptake of C. roseus-AgNPs occurs via endocytosis}

Endocytosis involves the formation of small membrane vesicles $(60-120 \mathrm{~nm})$ that transports various molecules or cargos from the plasma membrane to the cytoplasm. Though there are several types of endocytosis, previous studies have shown that clathrin dependent endocytosis and macropinocytosis are the major routes of transportation of AgNPs into the cells [59]. The observations also agree with the results reported by Treuel et al. (2013) that the endocytosis has been demonstrated to be a key mechanism in driving the cellular uptake of AgNPs, with NPs entering cells via early endosomes, late endosomes, and lysosomes [60]. In this study, a few genes such as ARF6, EHD2, FGFR3, RhoA, EEA1, VPS28, VPS25, TSG101, were upregulated, suggesting that the uptake of C. roseus-AgNPs can occur via the clathrin-dependent or clathrin-independent endocytosis pathway. ARF6 gene, also known as ADP-ribosylation factor 6, is a small-GTPase that regulates endocytic membrane trafficking and actin remodelling [61]. The upregulation of ARF6 gene in this study is consistent with the findings of Tanabe et al. (2005), which suggest that ARF6 gene regulates the membrane trafficking between the plasma membrane and endosome via clathrin-dependent or clathrin-independent endocytosis [62]. Interestingly, our study demonstrated an upregulation of EHD2 gene, which encodes a member of the EH domain-containing protein family. EHD2 protein has a N-terminal domain that interacts with the actin cytoskeleton and a C-terminal EH domain that binds to an $\mathrm{EH}$ domain-binding protein [63]. This interaction appears to link clathrin-dependent endocytosis and actin, implying that this gene is involved in the endocytic pathway, particularly clathrin-dependent endocytosis [64]. Previous study by Morén et al (2012) showed that the overexpression of EHD2 gene inhibited the formation of caveolae [62]. These findings suggests that clathrin-dependent endocytosis was one of the major uptake mechanisms of C. roseus-AgNPs, while ruling out the involvement of possible involvement of caveolindependant endocytosis.

Another interesting finding in this study is the potential involvement of macropinocytosis, attributable to the upregulation of $R h o A$ gene macropinocytosis. This gene encodes a member of the Rho family of small GTPases, which regulates macropinocytosis via active and inactive GTP-binding while simultaneously play an important role in remodeling of the actin skeleton during macropinocytosis [65, 66]. According to Pertz et al. (2006), after the macropinocytic cups closed to form macropinosomes, the expression of another Rho subtype, RhoA, increased significantly [66]. This corroborates our findings in this study 
on the RhoA gene upregulation, which suggests that C. roseus-AgNPs uptake also could occur via macropinocytosis. The overexpression of EEA1 (early endosome antigen 1) in this study clearly indicated that the formation of early endosomes occurs during the uptake of C. roseus-AgNPs. This finding is consistent with prior work, which demonstrated the high frequency of EEA1 gene in early endosomes that are the primary sorting station in the endocytic pathway [67]. On the other hand, TSG101 and VPS28 genes are involved in late endosomal trafficking [68]; the upregulation of TSG101 and VPS28 genes in this study suggest that late endosome was formed during the C. roseus-AgNPs uptake. This finding was in line with previous study, where the expression of Tumor susceptibility gene 101 protein (TSG101) and Vacuolar protein sorting-associated protein 28 homolog (VPS28) was found to be increased [69]. The upregulation of the stress-responsive genes as mentioned previously in our study is also indicative of the successful uptake of $C$. roseus-AgNPs into the HepG2 cells, as the generation of free radicals that induced stress in the cells can be caused by the leaching of Ag+ from AgNPs into cytosol, because of high acidic lysosome rupture. TFRC gene encodes a cell surface receptor necessary for cellular uptake by the process of receptor-mediated endocytosis [70]. The downregulation of the TFRC gene in this study suggests that the expression of the gene was induced to reduce endocytosis via negative feedback regulation as a response of cellular homeostasis. Our finding also is in tandem with the findings of Wang et al. (2018), who have also noticed the drop in the expression of TFRC gene, which could be due to negative feedback for defensive actions [71].

\subsection{The uptake of C. roseus-AgNPs causes cell cycle arrest}

Cancer progression is associated with the aberrancy in cell cycle, such as the anomalous expression of cyclin-dependent kinases (CDKs) [72]. CDKs are usually highly expressed, causing the uncontrolled proliferation of cancer cells [73]. Upon the treatment of the HepG2 cells with C. roseus-AgNPs, CDK4, CDK2 were found to be downregulated, implying the antagonistic effect of the nanoparticles against the cell cycle protein. A previous study had reported that the blockage of Go/G1 was accompanied by the downregulation of the cell cycle regulators $C D K 4$ and $C D K 2$ [74]. In this study, the downregulation of $C D K 4$ and $C D K 2$ suggested that $C$. roseus-AgNPs was arrested at Go/G1. Another important observation is the upregulation of GADD45A, which caused a decrease in the Sphase kinase-associated protein 2 (SKP2) expression. Overexpression of SKP2 is associated with the cell cycle progression and as the $S K P 2$ expression was found to be reduced in the present study, it is surmised that the cell proliferation is being forestalled. Moreover, the reduced expression of SKP2 is also associated with the increased expression of Cyclin-dependent kinase inhibitor 1 (CDKN1A), which is an inhibitor of cell cycle progression by inhibiting the activity of cyclin-dependent kinases expression [75] upon the treatment with C. roseus-AgNPs. The upregulation of CDKN1A corroborates the anticancer activities of $C$. roseus-AgNPs that can induce cell cycle arrest. MCM3 is a member of Minichromosome Maintenance 3 (MCM3) that is associated with tumor invasiveness [76]. The treatment of the C. roseus-AgNPs caused the downregulation of MCM3, in HepG2 cells, ratifying the anticancer activities of $C$. roseus-AgNPs in alleviating tumor aggressiveness.

The overall proposed mechanism is as depicted in Figure 11, that consists of clathrin-dependent and clathrin-independent endocytosis. The signaling pathways indicate the involvement of the up and down regulated genes in various cellular organelles. The understanding of cellular and molecular mechanisms would provide a string justification of the rationale of C. roseus-AgNPs as anticancer compounds for liver cancer therapy. 


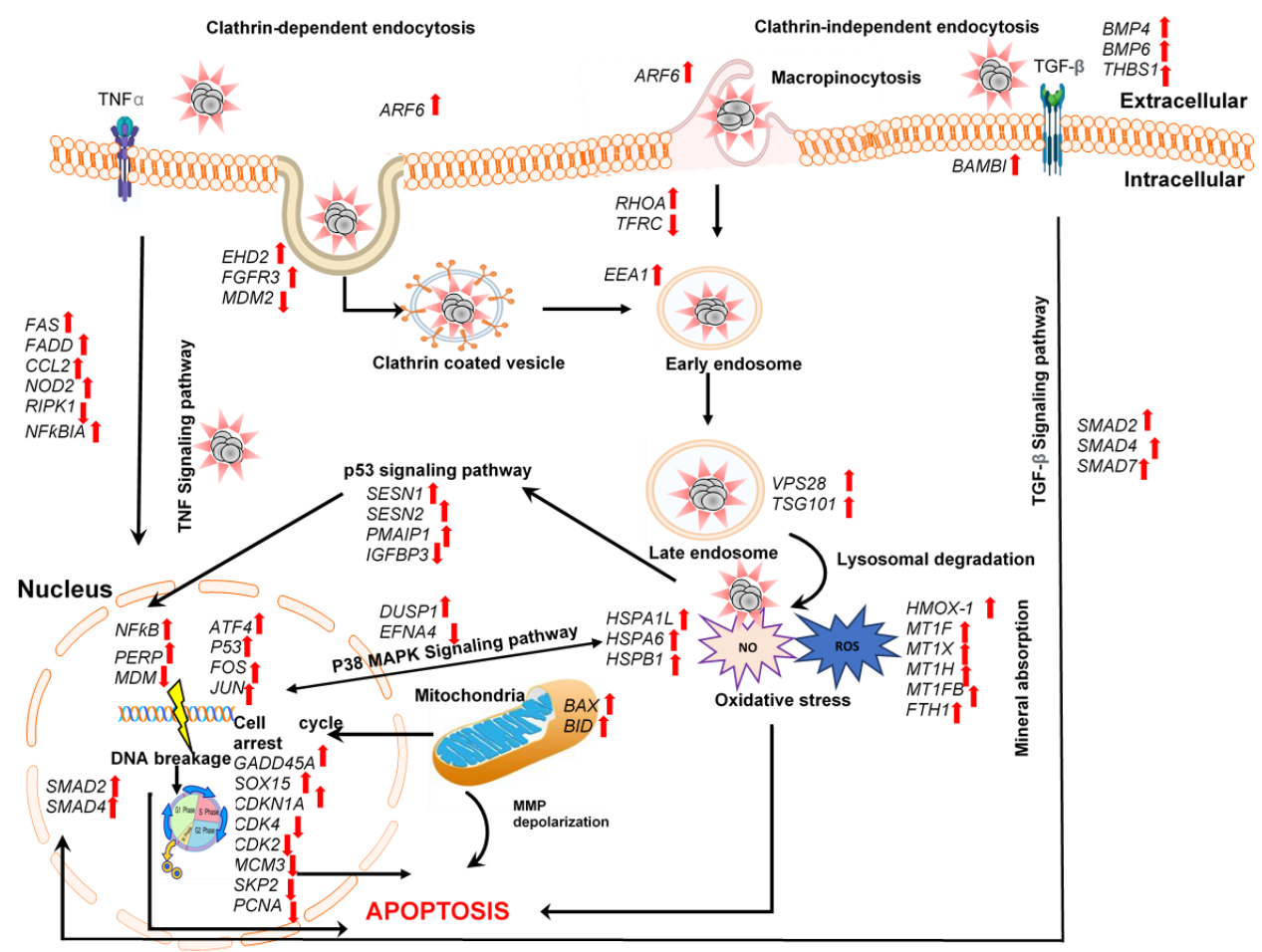

Figure 11. Cellular and molecular involved in anti-cancer activity of HepG2 cell treated with C. roseus-AgNPs.

\section{Conclusions}

In this study, the treatment of HepG2 cells with C. roseus-AgNPs has resulted in the increase of the expression of tumor suppressor genes, apoptotic genes, and activation of signal transduction pathway such as mitogen-activated protein kinase (MAPK) signaling pathway, endocytosis signaling pathway, TNF signaling pathway, TGF-Beta signaling pathway as well as cell cycle arrest. Collectively, the findings from our study have demonstrated the anti-cancer properties of $C$. roseus-AgNPs, with insignificant effect on normal cells. The therapeutic property of the C. roseus-AgNPs should be further explored in the future as part of the endeavours to surrogate or complement the current conventional chemotherapeutic-based intervention.

\section{Patents}

Author Contributions: Conceptualization, N.H.A.; methodology, N.H.A.; validation, N.A.A; formal analysis, N.A.A and S.A.A.B.; investigation, N.A.A; resources, N.H.A.; data curation, N.A.A, S.A.A.B, M.C. and N.H.A.; writing-original draft preparation, N.A.A.; writing-review and editing, N.H.A. and M.C.; supervision, N.H.A and M.C.; project administration, N.H.A; funding acquisition, N.H.A. All authors have read and agreed to the published version of the manuscript.

Funding: Please add: This study was funded by Fundamental Research Grant Scheme (FRGS), with Reference Code: FRGS/1/2015/SG03/USM/03/1 under the Ministry of Higher Education Malaysia.

Acknowledgments: We would like to offer special appreciation to all laboratory staffs and postgraduate students under the laboratory of Oncological and Radiological Sciences Cluster, Advanced Medical and Dental Institute for their guidance, assistance, and support.

Conflicts of Interest: The authors declare no conflict of interest.

\section{Appendix A}

Refer to the Supplementary data.

\section{References}


1. Sankar R, Karthik A, Prabu A, Karthik S, Shivashangari KS, Ravikumar V. Origanum vulgare mediated biosynthesis of silver nanoparticles for its antibacterial and anticancer activity. Colloids Surfaces B Biointerfaces [Internet]. 2013 Aug 1 [cited 2018 Mar 25];108:80-4. Available from: http://dx.doi.org/10.1016/j.colsurfb.2013.02.033

2. Zhang Y, Li M, Gao X, Chen Y, Liu T. Nanotechnology in cancer diagnosis: Progress, challenges and opportunities [Internet]. Vol. 12, Journal of Hematology and Oncology. BioMed Central; 2019 [cited 2021 Jul 7]. p. 1-13. Available from: https://jhoonline.biomedcentral.com/articles/10.1186/s13045-019-0833-3

3. Piao MJ, Kang KA, Lee IK, Kim HS, Kim S, Choi JJYJ, et al. Silver nanoparticles induce oxidative cell damage in human liver cells through inhibition of reduced glutathione and induction of mitochondria-involved apoptosis. Toxicol Lett [Internet]. 2011 Feb 25 [cited 2018 Mar 25];201(1):92-100. Available from: http://dx.doi.org/10.1016/j.toxlet.2010.12.010

4. Ferrari M. Cancer nanotechnology: opportunities and challenges. Nat Rev Cancer [Internet]. 2005 Mar 1 [cited 2018 Mar 21];5(3):161-71. Available from: http://www.nature.com/articles/nrc1566

5. Ghozali SZ, Ismail MN, Ahmad NH. Characterisation of Silver Nanoparticles using a Standardised C. roseus Aqueous Extract. Malaysian J Med Heal Sci. 2018;14(SUPP1):120-5.

6. Ahmad N, Sharma S. Green Synthesis of Silver Nanoparticles Using Extracts of Ananas comosus. Green Sustain Chem [Internet]. 2012 [cited 2018 Mar 22];02(04):141-7. Available from: http://dx.doi.org/10.4236/gsc.2012.24020

7. Jeyaraj M, Rajesh M, Arun R, MubarakAli D, Sathishkumar G, Sivanandhan G, et al. An investigation on the cytotoxicity and caspase-mediated apoptotic effect of biologically synthesized silver nanoparticles using Podophyllum hexandrum on human cervical carcinoma cells. Colloids Surfaces B Biointerfaces [Internet]. 2013 Feb [cited 2019 May 18];102:708-17. Available from: http://dx.doi.org/10.1016/j.colsurfb.2012.09.042

8. Khan M, Khan M, Adil SF, Tahir MN, Tremel W, Alkhathlan HZ, et al. Green synthesis of silver nanoparticles mediated by Pulicaria glutinosa extract. Int J Nanomedicine [Internet]. 2013 Apr 17 [cited 2021 Jul 7];8(1):1507-16. Available from: https://www.dovepress.com/green-synthesis-of-silver-nanoparticles-mediated-by-pulicaria-glutinos-peer-reviewedfulltext-article-IJN

9. Kavitha S, Kalai Kovan T, Vijaya Bharathi R. In vitro antioxidant and anticancer studies on the leaf of Acalypha indica. Biomed Pharmacol J. 2009 Feb 16;2(2):431-5.

10. Valsalam S, Agastian P, Arasu MV, Al-Dhabi NA, Ghilan AKM, Kaviyarasu K, et al. Rapid biosynthesis and characterization of silver nanoparticles from the leaf extract of Tropaeolum majus L. and its enhanced in-vitro antibacterial, antifungal, antioxidant and anticancer properties. J Photochem Photobiol B Biol. 2019 Feb 1;191(26):65-74.

11. Meek B, Doull J. Pragmatic challenges for the vision of toxicity testing in the 21st century in a regulatory context: Another ames test? ... or a new edition of "the red book"? Toxicol Sci [Internet]. 2009 [cited 2020 Jun 14];108(1):19-21. Available from: https://academic.oup.com/toxsci/article-abstract/108/1/19/1676322

12. Schoonen WGEJ, De Roos JADM, Westerink WMA, Débiton E. Cytotoxic effects of 110 reference compounds on HepG2 cells and for 60 compounds on HeLa, ECC-1 and CHO cells. II Mechanistic assays on NAD(P)H, ATP and DNA contents. Toxicol Vitr. 2005 Jun 1;19(4):491-503.

13. Walker JM, Kumar S, Kashyap P, Rovin BH, Wurst E, Kohan DE, et al. Antiproliferative effect of silver nanoparticles synthesized using amla on Hep2 cell line. Kidney Int [Internet]. 2015;4(1):109. Available from: http://dx.doi.org/10.1038/ki.1991.312

14. Wang $\mathrm{CH}$, Wang GC, Wang Y, Zhang XQ, Huang XJ, Zhang DM, et al. Cytotoxic dimeric indole alkaloids from C. roseus. Fitoterapia. 2012 Jun 1;83(4):765-9.

15. Arisha MH, Aboelnasr H, Ahmad MQ, Liu Y, Tang W, Gao R, et al. Transcriptome sequencing and whole genome expression profiling of hexaploid sweetpotato under salt stress. BMC Genomics [Internet]. 2020 Mar 4 [cited 2021 Jun 30];21(1):1-18. Available from: https://doi.org/10.1186/s12864-020-6524-1

16. Coward SM, Selden C, Mantalaris A, Hodgson HJF. Proliferation rates of HepG2 cells encapsulated in alginate are increased 
in a microgravity environment compared with static cultures. Artif Organs. 2005 Feb;29(2):152-8.

17. Schroeder A, Mueller O, Stocker S, Salowsky R, Leiber M, Gassmann M, et al. The RIN: An RNA integrity number for assigning integrity values to RNA measurements. BMC Mol Biol [Internet]. 2006 Jan 31 [cited 2020 Apr 7];7(1):3. Available from: http://bmcmolbiol.biomedcentral.com/articles/10.1186/1471-2199-7-3

18. Kim D, Langmead B, Salzberg SL. HISAT: A fast spliced aligner with low memory requirements. Nat Methods. 2015 Mar 31;12(4):357-60.

19. Langmead B, Salzberg SL. Fast gapped-read alignment with Bowtie 2. Nat Methods. 2012 Apr 4;9(4):357-9.

20. Li B, Dewey CN. RSEM: Accurate transcript quantification from RNA-Seq data with or without a reference genome. BMC Bioinformatics. 2011 Aug 4;12(1):1-16.

21. Ghozali SZ, Vuanghao L NA. Biosynthesis and Characterization of Silver Nanoparticles using C. roseus Leaf Extract and its Proliferative Effects on Cancer Cell Lines. J Nanomed Nanotechnol. 2015;06(04):1-10.

22. Rosarin FS, Arulmozhi V, Nagarajan S, Mirunalini S. Antiproliferative effect of silver nanoparticles synthesized using amla on Hep2 cell line. Asian Pac J Trop Med [Internet]. 2013;6(1):1-10. Available from: http://dx.doi.org/10.1016/S19957645(12)60193-X

23. Halkai K, Mudda J, Shivanna V, Patil V, Rathod V, Halkai R. Cytotoxicity evaluation of fungal-derived silver nanoparticles on human gingival fibroblast cell line: An in vitro study. J Conserv Dent [Internet]. 2019 Mar 1 [cited 2020 Sep 1];22(2):1603. Available from: /pmc/articles/PMC6519193/?report=abstract

24. Sriram MI, Kanth SBM, Kalishwaralal K, Gurunathan S. Antitumor activity of silver nanoparticles in Dalton's lymphoma ascites tumor model. Int J Nanomedicine. 2010;5(1):753-62.

25. Halkai K, Mudda J, Shivanna V, Patil V, Rathod V, Halkai R. Cytotoxicity evaluation of fungal-derived silver nanoparticles on human gingival fibroblast cell line: An in vitro study. J Conserv Dent [Internet]. 2019 Mar 1 [cited 2020 Aug 31];22(2):1603. Available from: /pmc/articles/PMC6519193/?report=abstract

26. Składanowski M, Golinska P, Rudnicka K, Dahm H, Rai M. Evaluation of cytotoxicity, immune compatibility and antibacterial activity of biogenic silver nanoparticles. Med Microbiol Immunol. 2016 Dec 1;205(6):603-13.

27. Mohanta YK, Panda SK, Bastia AK, Mohanta TK. Biosynthesis of silver nanoparticles from Protium serratum and investigation of their potential impacts on food safety and control. Front Microbiol. 2017 Apr 18;8(APR).

28. Khorrami S, Zarrabi A, Khaleghi M, Danaei M, Mozafari MR. Selective cytotoxicity of green synthesized silver nanoparticles against the MCF-7 tumor cell line and their enhanced antioxidant and antimicrobial properties. Int J Nanomedicine [Internet]. 2018 [cited 2020 Aug 31];13:8013-24. Available from: /pmc/articles/PMC6267361/?report=abstract

29. Siddiqui S, Singh A, Ali S, Yadav M, Pandey V, Sharma D. Metallothionein: Potential therapeutic target for osteosarcoma. J Oncol Sci. 2019 Apr 1;5(1):13-8.

30. Zuberek M, Paciorek P, Bartosz G, Grzelak A. Silver nanoparticles can attenuate nitrative stress. Redox Biol. 2017 Apr 1;11:646-52.

31. Min KS. The physiological significance of metallothionein in oxidative stress [Internet]. Vol. 127, Yakugaku Zasshi. 2007 [cited 2020 May 7]. p. 695-702. Available from: https://www.jstage.jst.go.jp/article/yakushi/127/4/127_4_695/_article/-char/ja/ Woo S, Yum S, Jung JH, Shim WJ, Lee CH, Lee TK. Heavy metal-induced differential gene expression of metallothionein in Javanese medaka, Oryzias javanicus. Mar Biotechnol. 2006;8(6):654-62.

33. Maheshwari K, Silva RM, Guajardo-Morales L, Garlet GP, Vieira AR, Letra A. Heat Shock 70 Protein Genes and Genetic Susceptibility to Apical Periodontitis. J Endod [Internet]. 2016 Oct 1 [cited 2021 Jun 25];42(10):1467-71. Available from: /pmc/articles/PMC5035602/

34. Jiang X, Micləuş T, Wang L, Foldbjerg R, Sutherland DS, Autrup H, et al. Fast intracellular dissolution and persistent cellular uptake of silver nanoparticles in CHO-K1 cells: Implication for cytotoxicity. Nanotoxicology. 2015;9(2):181-9.

35. Araujo JA, Zhang M, Yin F. Heme oxygenase-1, oxidation, inflammation, and atherosclerosis. Front Pharmacol. 2012;3 


\section{JUL(July):1-17.}

36. Gurunathan S, Qasim M, Park C, Yoo H, Choi DY, Song H, et al. Cytotoxicity and transcriptomic analysis of silver nanoparticles in mouse embryonic fibroblast cells. Int J Mol Sci [Internet]. 2018 Nov 16 [cited 2021 Jul 13];19(11):3618. Available from: https://www.mdpi.com/1422-0067/19/11/3618/htm

37. Azhar NA, Ghozali SZ, Abu Bakar SA, Lim V, Ahmad NH. Suppressing growth, migration, and invasion of human hepatocellular carcinoma HepG2 cells by C. roseus-silver nanoparticles. Toxicol Vitr. 2020 Sep 1;67(10):4910.

38. Xue Y, Wang J, Huang Y, Gao X, Kong L, Zhang T, et al. Comparative cytotoxicity and apoptotic pathways induced by nanosilver in human liver HepG2 and L02 cells. Hum Exp Toxicol [Internet]. 2018 Dec 16 [cited 2020 May 7];37(12):1293-309. Available from: http://journals.sagepub.com/doi/10.1177/0960327118769718

39. de Lima R, Seabra AB, Durán N. Silver nanoparticles: A brief review of cytotoxicity and genotoxicity of chemically and biogenically synthesized nanoparticles. J Appl Toxicol. 2012;32(11):867-79.

40. Wang J, Che B, Zhang LW, Dong G, Luo Q, Xin L. Comparative genotoxicity of silver nanoparticles in human liver HepG2 and lung epithelial A549 cells. J Appl Toxicol. 2017;37(4):495-501.

41. Appella E, Anderson CW. Post-translational modifications and activation of p53 by genotoxic stresses. Eur J Biochem. 2001;268(10):2764-72.

42. Elston R, Inman GJ. Crosstalk between p53 and TGF- $\beta$ Signalling . J Signal Transduct. 2012;2012:1-10.

43. Sahu SC, Zheng J, Yourick JJ, Sprando RL, Gao X. Toxicogenomic responses of human liver HepG2 cells to silver nanoparticles. J Appl Toxicol. 2015;35(10):1160-8.

44. Eom HJ, Choi J. p38 MAPK activation, DNA damage, cell cycle arrest and apoptosis as mechanisms of toxicity of silver nanoparticles in Jurkat T cells. Environ Sci Technol [Internet]. 2010 Sep 24 [cited 2021 Feb 8];44(21):8337-42. Available from: https://pubs.acs.org/doi/abs/10.1021/es1020668

45. Su MQ, Zhou YR, Rao X, Yang H, Zhuang XH, Ke XJ, et al. Baicalein induces the apoptosis of HCT116 human colon cancer cells via the upregulation of DEPP/ Gadd45a and activation of MAPKs. Int J Oncol [Internet]. 2018 Aug 1 [cited 2021 Jun 30];53(2):750-60. Available from: http://www.spandidos-publications.com/10.3892/ijo.2018.4402/abstract

46. Brown L, Benchimol S. The involvement of MAPK signaling pathways in determining the cellular response to p53 activation: Cell cycle arrest or apoptosis. J Biol Chem. 2006 Feb 17;281(7):3832-40.

47. LIU Z. Molecular mechanism of TNF signaling and beyond. Cell Res 2005151 [Internet]. 2005 [cited 2021 Jul 22];15(1):24-7. Available from: https://www.nature.com/articles/7290259

48. Zhu N, Ware CF, Lai MMC. Hepatitis C virus core protein enhances FADD-mediated apoptosis and suppresses TRADD signaling of tumor necrosis factor receptor. Virology. 2001 May 10;283(2):178-87.

49. Matysiak-Kucharek M, Czajka M, Jodłowska-Jędrych B, Sawicki K, Wojtyła-Buciora P, Kruszewski M, et al. Two sides to the same coin-cytotoxicity vs. Potential metastatic activity of AgNPs relative to triple-negative human breast cancer MDA-MB436 cells. Molecules [Internet]. 2020 May 1 [cited 2021 Aug 11];25(10):2357. Available from: https://pubmed.ncbi.nlm.nih.gov/32443890/

50. Iwasaki Y, Suganami T, Hachiya R, Shirakawa I, Kim-Saijo M, Tanaka M, et al. Activating transcription factor 4 links metabolic stress to interleukin-6 expression in macrophages. Diabetes [Internet]. 2014 [cited 2021 Jul 22];63(1):152-61. Available from: http://diabetes.diabetesjournals.org/lookup/suppl/doi:10.2337/db13-0757/-/DC1.

51. Jaco I, Annibaldi A, Lalaoui N, Wilson R, Tenev T, Laurien L, et al. MK2 Phosphorylates RIPK1 to Prevent TNF-Induced Cell Death. Mol Cell. 2017 Jun 1;66(5):698-710.e5.

52. Qiu X, Zhuang M, Lu Z, Liu Z, Cheng D, Zhu C, et al. RIPK1 suppresses apoptosis mediated by TNF and caspase-3 in intervertebral discs. J Transl Med [Internet]. 2019 Apr 27 [cited 2021 Jul 22];17(1):1-14. Available from: https://translationalmedicine.biomedcentral.com/articles/10.1186/s12967-019-1886-3

53. Wei W, Zhao X, Zhu J, Zhang L, Chen Y, Zhang B, et al. LncRNA-u50535 promotes the progression of lung cancer by 
activating CCL20/ERK signaling. Oncol Rep [Internet]. 2019 Nov 1 [cited 2021 Jul 23];42(5):1946-56. Available from: http://www.spandidos-publications.com/10.3892/or.2019.7302/abstract

54. Zaba LC, Fuentes-Duculan J, Eungdamrong NJ, Johnson-Huang LM, Nograles KE, White TR, et al. Identification of TNFrelated apoptosis-inducing ligand and other molecules that distinguish inflammatory from resident dendritic cells in patients with psoriasis. J Allergy Clin Immunol. 2010 Jun 1;125(6):1261-1268.e9.

55. Ramesh S, Wildey GM, Howe PH. Transforming growth factor $\beta$ (TGF $\beta$ )-induced apoptosis: The rise \& fall of Bim. Cell Cycle. 2009;8(1):11-7.

56. Pardali K, Moustakas A. Actions of TGF- $\beta$ as tumor suppressor and pro-metastatic factor in human cancer. Vol. 1775, Biochimica et Biophysica Acta - Reviews on Cancer. Elsevier; 2007. p. 21-62.

57. Syed V. TGF- $\beta$ Signaling in Cancer. J Cell Biochem [Internet]. 2016 Jun 1 [cited 2021 Jul 13];117(6):1279-87. Available from: https://onlinelibrary.wiley.com/doi/full/10.1002/jcb.25496

58. Zhang T, Chen HS, Wang LF, Bai MH, Wang YC, Jiang XF, et al. Ellagic acid exerts anti-proliferation effects via modulation of Tgf-B/Smad3 signaling in MCF-7 breast cancer cells. Asian Pacific J Cancer Prev [Internet]. 2014 [cited 2021 Jul 13];15(1):273-6. Available from: http://dx.doi.org/10.7314/

59. Kaksonen M, Roux A. Mechanisms of clathrin-mediated endocytosis [Internet]. Vol. 19, Nature Reviews Molecular Cell Biology. Nature Publishing Group; 2018 [cited 2021 Jul 13]. p. 313-26. Available from: https://www.nature.com/articles/nrm.2017.132

60. Treuel L, Jiang X, Nienhaus GU. New views on cellular uptake and trafficking of manufactured nanoparticles [Internet]. Vol. 10, Journal of the Royal Society Interface. The Royal Society; 2013 [cited 2021 Jul 13]. p. 1098. Available from: /pmc/articles/PMC3627074/

61. Tanabe K, Torii T, Natsume W, Braesch-Andersen S, Watanabe T, Satake M. A novel GTPase-activating protein for ARF6 directly interacts with clathrin and regulates clathrin-dependent endocytosis. Mol Biol Cell [Internet]. 2005 Apr [cited 2021 Jul 14];16(4):1617-28. Available from: /pmc/articles/PMC1073646/

62. Morén B, Shah C, Howes MT, Schieber NL, McMahon HT, Parton RG, et al. EHD2 regulates caveolar dynamics via ATPdriven targeting and oligomerization. Mol Biol Cell [Internet]. 2012 Feb 9 [cited 2021 Jul 14];23(7):1316-29. Available from: https://www.molbiolcell.org/doi/abs/10.1091/mbc.e11-09-0787

63. Benjamin S, Weidberg H, Rapaport D, Pekar O, Nudelman M, Segal D, et al. EHD2 mediates trafficking from the plasma membrane by modulating Rac1 activity. Biochem J [Internet]. 2011 Nov 1 [cited 2021 Jul 14];439(3):433-42. Available from: https://pubmed.ncbi.nlm.nih.gov/21756249/

64. Yang X, Ren H, Yao L, Chen X, He A. Role of EHD2 in migration and invasion of human breast cancer cells. Tumor Biol [Internet]. 2015 May 28 [cited 2021 Jul 14];36(5):3717-26. Available from: https://pubmed.ncbi.nlm.nih.gov/25557791/

65. Ridley AJ. Rho GTPases and actin dynamics in membrane protrusions and vesicle trafficking [Internet]. Vol. 16, Trends in Cell Biology. Trends Cell Biol; 2006 [cited 2021 Jul 15]. p. 522-9. Available from: https://pubmed.ncbi.nlm.nih.gov/16949823/

66. Patel JC, Galán JE. Differential activation and function of Rho GTPases during Salmonella-host cell interactions. J Cell Biol [Internet]. 2006 [cited 2021 Jul 15];175(3):453-63. Available from: https://rupress.org/jcb/article/175/3/453/34314

67. Kamentseva R, Kosheverova V, Kharchenko M, Zlobina M, Salova A, Belyaeva T, et al. Functional cycle of EEA1-positive early endosome: Direct evidence for pre-existing compartment of degradative pathway. PLoS One [Internet]. 2020 May 1 [cited 2021 Jul 15];15(5):e0232532. Available from: https://journals.plos.org/plosone/article?id=10.1371/journal.pone.0232532

68. Wagenaar TR, Tolstykh T, Shi C, Jiang L, Zhang J, Li Z, et al. Identification of the endosomal sorting complex required for transport-I (ESCRT-I) as an important modulator of anti-miR uptake by cancer cells. Nucleic Acids Res [Internet]. 2015 Jan 30 [cited 2021 Jul 15];43(2):1204-15. Available from: https://academic.oup.com/nar/article/43/2/1204/2414737

69. Bishop N, Woodman P. TSG101/Mammalian VPS23 and Mammalian VPS28 Interact Directly and Are Recruited to VPS4induced Endosomes. J Biol Chem [Internet]. 2001 Apr 13 [cited 2021 Jul 15];276(15):11735-42. Available from: 
http://www.jbc.org/article/S0021925819460456/fulltext

70. NCBI. TFRC transferrin receptor [Homo sapiens (human)] Gene ID: 7037 [Internet]. [cited 2021 Jul 15]. Available from: https://www.ncbi.nlm.nih.gov/gene/7037

71. Wang Y, Xiong L, Wu T, Zhang T, Kong L, Xue Y, et al. Analysis of differentially changed gene expression in EA.hy926 human endothelial cell after exposure of fine particulate matter on the basis of microarray profile. Ecotoxicol Environ Saf. 2018 Sep 15;159(10):213-20.

72. Otto T, Sicinski P. Cell cycle proteins as promising targets in cancer therapy [Internet]. Vol. 17, Nature Reviews Cancer. Nature Publishing Group; 2017 [cited 2021 Jul 13]. p. 93-115. Available from: https://www.nature.com/articles/nrc.2016.138

73. Kleinsimon S, Longmuss E, Rolff J, Jäger S, Eggert A, Delebinski C, et al. GADD45A and CDKN1A are involved in apoptosis and cell cycle modulatory effects of viscumTT with further inactivation of the STAT3 pathway. Sci Rep. 2018;8(1):1-14.

74. E. Tamura R, F. de Vasconcellos J, Sarkar D, A. Libermann T, B. Fisher P, F. Zerbini L. GADD45 Proteins: Central Players in Tumorigenesis. Curr Mol Med. 2012 Aug 4;12(5):634-51.

75. Besson A, Dowdy SF, Roberts JM. CDK Inhibitors: Cell Cycle Regulators and Beyond. Vol. 14, Developmental Cell. Cell Press; 2008. p. 159-69.

76. Yu S, Wang G, Shi Y, Xu H, Zheng Y, Chen Y. MCMs in Cancer: Prognostic Potential and Mechanisms. Vol. 2020, Analytical Cellular Pathology. Hindawi Limited; 2020. p. 1155. 